CZASOPISMO INŻYNIERII LĄDOWEJ, ŚRODOWISKA I ARCHITEKTURY JOURNAL OF CIVIL ENGINEERING, ENVIRONMENT AND ARCHITECTURE JCEEA, t. XXXIII, z. 63 (1/II/16), styczeń-marzec 2016, s. 323-330

Marcin STANIEK ${ }^{1}$

\title{
ZASTOSOWANIE SIECI NEURONOWYCH TYPU HOPFIELDA W DIAGNOSTYCE NAWIERZCHNI DROGOWYCH
}

\begin{abstract}
Artykuł dotyczy zagadnień diagnostyki nawierzchni drogowych z wykorzystaniem metod przetwarzania obrazów cyfrowych wspomaganych zastosowaniem sieci neuronowej typu Hopfielda w procesie wzajemnego dopasowania pikseli pary obrazów nawierzchni drogi. Para obrazów rejestrowana z wykorzystaniem stereowizyjnego mobilnego stanowiska pomiarowego, opracowanego przez autora, definiowana jest jako stereo-obraz drogi. W artykule opisano ograniczenia rozwiązań stereowizyjnych oraz przedstawiono problem niejednoznaczności dopasowania dla obszarów o jednakowej intensywności. Określono problem obiektów przesłaniających się w polu widzenia kamer, zidentyfikowano ograniczenia ciągłości wynikające z nagłej zmiany funkcji intensywności obrazów, oraz zwrócono uwagę na typowe ograniczenia związane z przetwarzaniem i rozpoznawaniem obrazów cyfrowych. Podczas implementacji sieci neuronowej zdefiniowano kryteria, których minimalizacja jako składowych funkcji energii pozwoliła na uzyskanie optymalnego dopasowania pikseli stereo-obrazów, tym samym właściwego odwzorowania nawierzchni drogowej. Do rozwiązania zadania optymalizacji wielokryterialnej zaproponowano kryteria maksymalizacji i jednoznaczności dopasowania pikseli oraz kolejności przyporządkowania sekwencji pikseli w obu stereo-obrazach, a także kryterium ciągłości mapy dysparycji. Opis matematyczny składowych energii sieci neuronowej określono w artykule. Ocenę zastosowania sieci neuronowej zdefiniowano jako różnicę pomiędzy pomiarami głębi z wykorzystaniem sieci neuronowej oraz bez jej zastosowania. Do oceny zaproponowanego rozwiązania przeprowadzono pomiary z wykorzystaniem mobilnego stanowiska stereowizyjnego, które porównano z pomiarami statycznymi z wykorzystaniem skanowania laserowego w zdefiniowanych przekrojach pomiarowych drogi. Zastosowana sieć neuronowa typu Hopfielda pozwoliła na zwiększenie liczby pikseli poprawnie przypisanych w procesie dopasowania pikseli stereo-obrazów. Zwiększyło to tym samym precyzję odwzorowania nawierzchni drogowej, tym samym oceny jest stanu.
\end{abstract}

Słowa kluczowe: ocena stanu nawierzchni drogowych, inspekcja drogi, stereowizja, diagnostyka stanu nawierzchni, przetwarzanie i rozpoznawanie obrazów

\footnotetext{
${ }^{1}$ Marcin Staniek, Politechnika Śląska, Wydział Transportu, 40-019 Katowice; ul. Krasińskiego 8, +48 3260341 15, marcin.staniek@polsl.pl
} 


\section{Wprowadzenie}

W utrzymaniu i zarządzaniu infrastrukturą drogową istotnym elementem jest diagnostyka nawierzchni drogowej. Stosowane metody oceny umożliwiają identyfikację odcinków drogi, których stan techniczny jest na poziomie niezadowalającym tym samym stanowiącym realne zagrożenie bezpiecznego poruszania się pojazdów. Działania w ramach diagnostyki nawierzchni w warunkach polskich określają Wytyczne Stosowania Diagnostyki Stanu Nawierzchni DSN [15]. Ocena i analiza otrzymanych parametrów pozwala na wnioskowanie dotyczące stanu technicznego badanego elementu sieci drogowej, określenie harmonogramu planowanych zabiegów naprawczych lub prac remontowych oraz ich zakresu. W podejściu długofalowym umożliwia planowanie zasobów finansowych niezbędnych do zapewnienia w należytej sprawności technicznej elementów infrastruktury drogowej.

Najnowsze rozwiązania stosowane $\mathrm{w}$ diagnostyce nawierzchni drogowych umożliwiają realizację pomiarów bez wpływu lub w ograniczonym zakresie na innych uczestników ruchu przy jednoczesnym zapewnieniu wysokiego poziomu dokładności pomiarów oraz kompleksowości identyfikowanych miar oceny. Dodatkowo pomiary realizowane $\mathrm{z}$ wykorzystaniem najnowszych rozwiązań mają charakter bezinwazyjny tzn. podczas realizacji badania urządzenia pomiarowe nie ingerują w konstrukcję drogi.

Systemy wizyjne oceny stanu nawierzchni tworzą szeroką grupę urządzeń wykorzystywanych w diagnostyce nawierzchni drogowych. Zastosowane w nich metody pomiaru oraz techniki przetwarzania i rozpoznawania obrazów w tym m.in. operacje: segmentacji, binaryzacji, dopasowania czy odwzorowania obrazów w trójwymiarowej przestrzeni pozwalają na ekstrakcję z obrazów, typowych uszkodzeń powierzchniowych drogi. $\mathrm{Z}$ ich wykorzystaniem możliwa jest identyfikacja i ewidencja takich uszkodzeń jak wyboje, łaty, deformacje, wykruszenia oraz spękania w tym podłużne, poprzeczne, siatkowe i technologiczne.

W literaturze przedmiotu odwzorowanie stereowizyjne stanowi wąski wycinek publikacji dotyczące wykorzystania technik wizyjnych w tym przetwarzania i rozpoznawania obrazów w diagnostyce nawierzchni drogowych. Jako główne do identyfikacji uszkodzeń drogowych kreują się metody stereowizyjne z wykorzystaniem oświetlenia liniowego lub projektora wyświetlającego określone wzorce świetlne. W procesie oceny drogi identyfikowane są odchylenia między teoretyczną informacją świetlną (dla idealnie równej powierzchni), a rzeczywistą zdeformowaną linią świetlną lub zdeformowanym wzorcem [4][7]. W artykułach wykazano możliwość odwzorowania zarówno nierówności poprzecznych jak i podłużnych oraz identyfikacji uszkodzeń nawierzchni z zastosowaniem miary korelacji krzyżowej obiektów wyznaczonych metodą detekcji narożników w stereo-obrazach. Skuteczny jest rozwój systemów identyfikacji stanu nawierzchni drogowej zaproponowany w artykułach [13][14] bazując na połączeniu danych wynikowych z kamer, w tym kamer liniowych, z oświetle- 
niem wskaźnikiem laserowym. Tego typu urządzenie pomiarowe do oceny stanu mikro i makro tekstury nawierzchni drogowej przedstawiono w artykule [4].

Na podstawie przeprowadzonego studium literatury przedmiotu, obserwacji pomiarów stanu nawierzchni, otrzymanych spostrzeżeń inspektorów realizujących pomiary, oraz samodzielnych przeprowadzonych badań i analiz opracował własne rozwiązanie stanowiska diagnostyki nawierzchni. Proponowane rozwiązanie bazujące na metodzie stereowizyjnego odwzorowania badanej nawierzchni drogi. Zaproponowany model opisu powierzchni drogi w odwzorowaniu przestrzennym umożliwia identyfikację, parametryzację i ewidencję uszkodzeń. Szczegółowy opis rozwiązania konstrukcyjnego stanowiska pomiarowego, zastosowanych algorytmów przetwarzania, rozpoznawania i dopasowania obrazów, w tym m. in. filtracji, korekcji, rektyfikacji oraz urządzenia elektroniczne do pomiaru przebytego dystansu, identyfikacji drgań czy lokalizacji pojazdu pomiarowego przedstawiono w publikacjach [8][9]. Ocenę zaproponowanej metody natomiast $\mathrm{w}$ artykule [10].

Niezależnie od dziedziny dla której implementowane jest rozwiązanie stereowizyjne ten rodzaj techniki badawczej posiada pewne ograniczenia. Elementarnym problemem dopasowania pikseli stereo-obrazów jest ich niejednoznaczność definiowana dla obszarów o jednakowej intensywności oraz obszarów zaszumionych lub zniekształconych. Zastosowanie metod identyfikacji charakterystycznych cech obiektów dla stereo-obrazów skutecznie zmniejsza przedstawiony problem. Niejednoznaczność dopasowania pikseli stereo-obrazów jest również identyfikowana na granicach obrazów, jednakże operacja zmniejszenia obszaru analizy obrazu względem rejestrowanego obszaru skutecznie eliminuje ten problem.

Inne ograniczenie rozwiązań stereowizyjnych dotyczy częściowego przesłaniania się obiektów w polu widzenia kamer systemu. Zastosowanie algorytmu zwrotnego pozwala na ich identyfikację i interpolację tych obszarów w procesie odwzorowania [1][3]. W diagnostyce nawierzchni drogowych ze względu na metodę realizacji pomiarów, budowę stanowiska pomiarowego i strukturę typowych uszkodzeń drogowych przyjęto, że przesłonięte obszary stanowią niewielką część analizowanych stereo-obrazów i zostają pominięte.

Kolejny problemem analizy stereo-obrazów dotyczy obszarów, w których występuje istotna zmiana intensywności obrazu np. w miejscach sąsiadowania obiektów, gdzie występuje krawędź rzeczywistego obiektu. Jego efektem jest rozmycie siatki dysparycji a tym samym niewłaściwe odwzorowanie rzeczywistości w modelu przestrzennym. W diagnostyce nawierzchni drogowych rejestrowana powierzchnia charakteryzuje się ciągłością opisu z wyłączeniem uszkodzeń drogi typu spękania i głębokie koleiny, i nie jest dominującym elementem negatywnego wpływu na proces odwzorowania.

Należy pamiętać, że oprócz przedstawionych problemów analizy głębi stereo-obrazów w procesie odwzorowania stanu nawierzchni drogowej występują typowe problemy przetwarzania obrazów cyfrowych jak zaszumienie, zniekształcenie czy nierównomierne oświetlenie. W opracowanym przez autora sta- 
nowisku stereowizyjnym [8], zastosowanie procedury kalibracji bazującej na przestrzennym wzorcu, pozwoliło na przeprowadzenie procesu rektyfikacji stereo-obrazów tym samym eliminację zniekształceń obrazów wynikającą z układów optycznych kamer oraz akwizycji obrazów w układzie niekanonicznym [3].

\section{Sieć neuronowa Hopfielda w procesie dopasowania stereo- obrazów}

Przedstawione problemy analizy głębi obrazów mają negatywny wpływ na precyzję odwzorowania powierzchni drogi, tym samym diagnostykę nawierzchni i wymusiły podjęcie próby opracowania, i zaimplementowania metod ograniczających ich występowanie. W dalszej części artykułu przedstawiono propozycję zastosowania sieci neuronowej typu Hopfielda w procedurze dopasowania pikseli stereo-obrazów w celu zmniejszenia przedstawionych problemów przetwarzania obrazów [5][12].

Uzyskanie optymalnego wyniku, najwyższej precyzji odwzorowania drogi, jest możliwe po rozwiązaniu zadania wielokryterialnego [2][11], dla zdefiniowanej funkcji energii sieci neuronowej (1), gdzie składowe funkcji energii odpowiadają określonym kryteriom optymalnego dopasowania pikseli stereo-obrazów.

$$
E=w_{1} E_{1}+w_{2} E_{2}+w_{3} E_{3}+w_{4} E_{4}+w_{5} E_{5}
$$

Zależność (1) uwzględnienia wagi istotności poszczególnych kryteriów rozwiązania zadania wielokryterialnego, dobierane indywidualnie do parametrów graficznych rejestrowanych obrazów.

Kryterium maksymalizacji dopasowania pikseli dotyczy współczynnika dopasowania CoVar stereo-obrazów, gdzie największa uzyskiwana wartość współczynnika odpowiada najlepszemu dopasowaniu punktów stereo-obrazów. Składową energii przyjętej sieci neuronowej dla tego kryterium określa zależność (2):

$$
E_{1}=-\sum_{i}^{n} \sum_{j}^{m} \sum_{i^{\prime}}^{n} \sum_{j^{\prime}}^{m} C_{i j, i^{\prime} j^{\prime}} v_{i j} v_{i^{\prime} j^{\prime}}
$$

gdzie: $C_{i j, i^{\prime} j^{\prime}}$ - współczynnik korelacji pary punktów stereo-obrazów $(i, j) i\left(i, j^{\prime}\right)$ $v_{i j}, v_{i{ }^{\prime}{ }^{\prime}}$ - potencjał wyjściowe neuronów $n e u_{i j}$ i $n e u_{i{ }^{\prime} j^{\prime}}$.

Kryterium jednoznaczności dopasowania pikseli identyfikuje czy jednemu pikselowi obrazu lewego odpowiada jeden piksel obrazu prawego i odwrotnie. Funkcję składową energii definiuje zależność (3):

$$
E_{2}=\sum_{i}^{n} \sum_{j}^{m} \sum_{\substack{j^{\prime} \\ j^{\prime} \neq j}}^{m} v_{i j} v_{i j^{\prime}}+\sum_{i}^{n} \sum_{k}^{m} \sum_{\substack{i^{\prime} \\ i^{\prime} \neq i}}^{n} v_{i j} v_{i^{\prime} j}
$$


Kryterium kolejności przyporządkowania pikseli oznacza, że zadanej sekwencji kolejnych pikseli lewego obrazu odpowiada analogiczna sekwencja pikseli prawego obrazu. Składową energii dla tego kryterium określa zależność (4):

$$
E_{3}=\sum_{i}^{n} \sum_{j}^{m} \sum_{j^{\prime}}^{j} v_{i j} v_{i+1, j^{\prime}} \sigma_{i, i+1}
$$

gdzie : $\sigma_{i, i+1}=1$ dla zgodności kolejności, w przeciwnym przypadku zero.

Kryterium ciągłości mapy dysparycji identyfikuje nagłe zmian wartości funkcji intensywności oraz eliminuje je poprzez „oddalenie” tymczasowego rozwiązania ze zbioru możliwych rozwiązań. Funkcję składową definiuje zależność (5):

$$
E_{4}=\sum_{i}^{n} \sum_{j}^{m} \sum_{j^{\prime}}^{m} v_{i j} v_{i+1, j^{\prime}} \sigma_{i, i+1} \xi_{i j, i^{\prime} j^{\prime}}
$$

gdzie: $\xi_{i j, i^{\prime} j^{\prime}}=\alpha$ dla $j^{\prime}>j$ - tolerowane odchylenie w przyjętym kryterium, w przeciwnym przypadku wzrost składowej energii.

\section{Ocena procesu dopasowania stereo-obrazów w diagnostyce nawierzchni drogowych}

Ocenę zasadności zastosowania sieci neuronowej w diagnostyce nawierzchni drogowych przeprowadzono na zbiorach danych pozyskanych z: (1) pomiarów mobilnych z wykorzystaniem stereowizyjnego stanowiska badawczego oraz (2) skanowania laserowego w wybranych przekrojach drogowych. Stanowisko skanowania laserowego pozwala na odwzorowanie rzeczywistej powierzchni drogi, w tym z uszkodzeniami, przy realizacji pomiarów z użyciem dalmierza laserowego. Na rysunku 1 przedstawiono mobilne stereowizyjne stanowisko pomiarowe, natomiast na rysunku 2 stanowisko skanowania laserowego - ,stanowisko wzorcowe".

Z wykorzystaniem stanowiska wzorcowego odwzorowano powierzchnię drogi (dalej jako wzorzec) o wymiarach $1100 \mathrm{~mm}$ na $850 \mathrm{~mm}$ w rozdzielczości $10 \mathrm{~mm}$ na $10 \mathrm{~mm}$ dla wybranych 15 przekrojów pomiarowych. Dla określonych punktów wzorca zidentyfikowano piksele stereo-obrazów stanowiące stereowizyjne odwzorowanie nawierzchni drogowej. Porównano pomiary głębi wzorca z pomiarami głębi bazującymi na odwzorowaniu nawierzchni drogi bez zastosowania sieci neuronowej i z zastosowaniem sieci neuronowej dla pomiarów mobilnych. W Tabeli 1 przedstawiono wyniki określając odpowiednio symbolami: A liczbę pikseli o pomiarze głębi różnym od wartości wzorcowej, B pro- 
cent wartości skorygowanych zgodnie $\mathrm{z}$ danymi wzorca, C procent wartości skorygowanych niewłaściwie oraz D procent wartości niezmiennych.

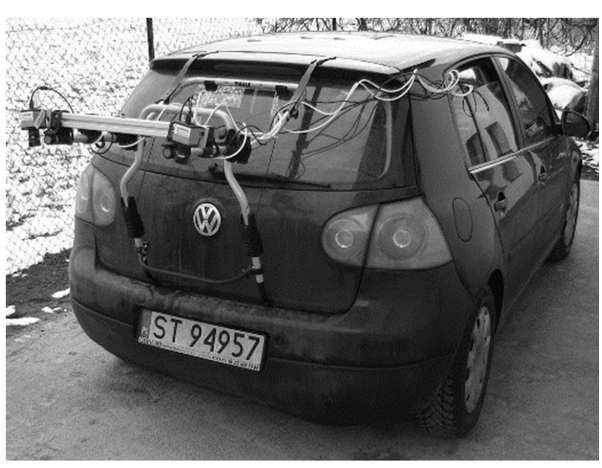

Rys. 1. Mobilne stanowisko pomiarowe

Fig. 1. Mobile test-bench

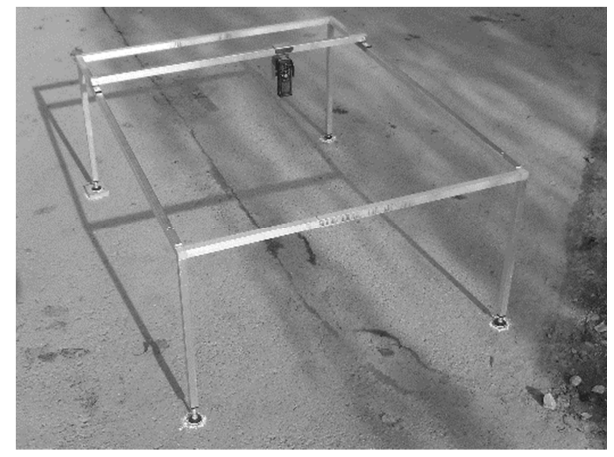

Rys. 2. Wzorcowe stanowisko pomiarowe

Fig. 2. Pattern test-bench

Tabela 1. Wyniki zastosowania sieci neuronowej typu Hopfielda

Table 1. Results of using Hopfield neural networks

\begin{tabular}{|c|c|c|c|c|}
\hline No. & $\mathbf{A}[\mathbf{p x}]$ & $\mathbf{B}[\boldsymbol{\%}]$ & $\mathbf{C}[\boldsymbol{\%}]$ & $\mathbf{D}[\boldsymbol{\%}]$ \\
\hline $\mathbf{1}$ & 280 & 74 & 21 & 5 \\
\hline $\mathbf{2}$ & 364 & 60 & 32 & 8 \\
\hline $\mathbf{3}$ & 343 & 54 & 27 & 19 \\
\hline $\mathbf{4}$ & 304 & 77 & 18 & 5 \\
\hline $\mathbf{5}$ & 241 & 71 & 17 & 12 \\
\hline $\mathbf{6}$ & 206 & 63 & 20 & 17 \\
\hline $\mathbf{7}$ & 253 & 57 & 33 & 10 \\
\hline $\mathbf{8}$ & 320 & 56 & 25 & 19 \\
\hline $\mathbf{9}$ & 271 & 58 & 24 & 18 \\
\hline $\mathbf{1 0}$ & 348 & 60 & 26 & 14 \\
\hline $\mathbf{1 1}$ & 348 & 56 & 33 & 11 \\
\hline $\mathbf{1 2}$ & 359 & 59 & 25 & 16 \\
\hline $\mathbf{1 3}$ & 243 & 67 & 25 & 8 \\
\hline $\mathbf{1 4}$ & 231 & 69 & 25 & 6 \\
\hline $\mathbf{1 5}$ & 320 & 74 & 14 & 12 \\
\hline
\end{tabular}

Zastosowanie sieci neuronowej typu Hopfielda w procesie dopasowania pikseli stereo-obrazów pozwala na zwiększeni precyzji dozorowania nawierzchni drogowej. Uzyskana średnia $63 \%$ wartości poprawnie skorygowanych pomiarów głębi z zastosowaniem sieci neutronowej dla przedstawionych przekrojów pomiarowych potwierdza wybrany kierunek prac. 


\section{Wnioski}

Diagnostyka nawierzchni drogowych z wykorzystaniem rozwiązań stereowizyjnych pozwala na szybką realizację pomiarów oraz kompleksowość odwzorowania jej stanu. Niezależnie od obszaru wykorzystania rozwiązań stereowizyjnych niejednoznaczność dopasowania pikseli stereo-obrazów, czyli wzajemnego dopasowania pikseli pary obrazów rejestrowanej drogi, jest newralgicznym elementem procesu odwzorowania. Właściwe dopasowanie pikseli jest problemem złożonym, musi uwzględniać zniekształcenia i uproszczenia operacji przekształceń optycznych oraz przesunięcie układów optoelektronicznych systemu pomiarowego.

Przedstawione rozwiązanie zastosowania sieci neuronowej typu Hopfielda pozwala na korekcję dopasowania pikseli stereo-obrazów, tym samym odwzorowanie nawierzchni drogowej z wyższą precyzją. Implementacja wybranej sieci neuronowej nie wymagała ingerencji $\mathrm{w}$ zastosowane algorytmy przetwarzania obrazów, rozwiązania konstrukcyjne stanowiska pomiarowego oraz parametry rejestracji obrazów. Uzyskane wyniki oceny dopasowania pikseli stereoobrazów dla obrazów nawierzchni drogowej potwierdziły słuszność zastosowania sieci neuronowej względem tradycyjnych miar wzajemnego dopasowania pikseli pary obrazów [3][11]. Tym samym, zaproponowane rozwiązanie zwiększa dokładność pomiarów stanu nawierzchni drogowych.

\section{Literatura}

[1] Batchelor B.G., Waltz F.M.: Intelligent machine vision: techniques, implementations and applications, 2001, Springer-Verlag UK.

[2] Cichocki A., Unbehauen R.: Neural networks for optimization and signal processing, Willey 1993, John Wiley \& Sons, Chichester.

[3] Cyganek B., Siebert P., An Introduction to 3D Computer Vision Techniques and Algorithms, 2009, John Wiley \& Sons, Chichester.

[4] Grace A.E., Pycock D., Tillotson H.T., Snaith M.S., Active shape from stereo for highway inspection, Machine Vision and Applications, 2000, pp. 7-15.

[5] Mańdziuk J.,: Sieci neuronowe typu Hopfielda. Teoria i przykłady zastosowań, Akademicka Oficyna Wydawnicza EXIT, 2000, Warszawa.

[6] Scharstein B., View Synthesis Using Stereo Vision, Lecture Notes in Computer Science 1582, 1999, Springer-Verlag, Berlin.

[7] Soatto M, S., Kosecka J., Sastry S.S., An invitation to 3-D vision: from images to geometric models, 2004, Springer-Verlag, New York.

[8] Staniek M., Pavement conditions diagnosis by means of stereoscopy, Proc. of the 58th Conference of Scientific Problems of Civil Engineering, 2012, pp. 358-359.

[9] Staniek M.: Diagnostyka stanu nawierzchni drogowej z wykorzystaniem pomiarów stereoskopowych. Zeszyty Naukowe Politechniki Rzeszowskiej, nr 283 z. 59, nr 3, 2012, pp. 339-346. 
[10] Staniek M.: Ocena dokładności stereowizyjnej metody inspekcji dróg. Budownictwo i architektura. vol. $13 \mathrm{nr}$ 4, 2014, s. 259-266.

[11] Tadeusiewicz R., Korbicz J., Rutkowski L., Duch W., Sieci neuronowe w inżynierii biomedycznej. Tom 9, ISBN 978-83-7837-024-6, Akademicka Oficyna Wydawnicza EXIT, 2013, Warszawa.

[12] Tsai C.T., Wang J.H., Sun Y.N.: Livet stereoscopic visualization by using Hopfield neural nets, Neural Computing and Applications, Vol. 7(3), 1998, pp. 229-237.

[13] Vilaça J. L., Fonseca J. C., Pinho A. M., Non-contact 3D acquisition system based on stereo vision and laser triangulation, Machine Vision and Applications 21(3), 2010, pp. 341-350.

[14] Wang K. C. P, Gong W., Tracy T., Nguyen V., Automated survey of pavement distress based on 2D and 3D laser images, MBTC DOT 3023 -Grant, 2011, Transportation Research Board.

[15] Zarządzenie nr 34 Generalnego Dyrektora Dróg Krajowych i Autostrad z dnia 30 kwietnia 2015 r. w sprawie diagnostyki stanu nawierzchni i jej elementów.

\title{
APPLICATION OF HOPFIELD NEURAL NETWORKS IN DIAGNOSIS OF ROAD PAVEMENT
}

\begin{abstract}
S u m m a r y
The paper presents an attempt to use Hopfield neural network in process of matching pixels of stereo-images recorded during road pavement diagnosis by vehicle equipped with stereo vision test-bench, developed by author of the paper. The paper describes the limitations of stereo vision solutions and presents the problem of ambiguity matching for the areas of equal intensity. The problems of obscuration objects in the camera view and continuity constraints of resulting from a sudden change in intensity function of images are presented. Typical limitations associated with the techniques of processing and recognition of digital images are highlighted. During the implementation of the neural network the constituents of energy function (criteria of optimization) were defined, what allow for optimum matching pixels of stereo-images, thus the mapping process of road surface is proper. To solve multi criteria optimization problem, the followings criteria were proposed: maximize and uniqueness of matching pixels and order assignment sequence of pixels in both stereo-images, as well as continuity of disparity map. The mathematical description of energy constituents of the neural network was determined in the article. Evaluation of the application neural network was defined as difference between the depth measurements using neural network and without its use. For evaluation of the proposed solution, the measurements using a stereo vision test-bench were performed and were compared with measurements using a laser scanning in selected measurement sections on road. Used of Hopfield neural network allows to increase the number of pixels correctly assigned on stereo-images in the matching process what increase the mapping precision of the road surface, thereby evaluation of road conditions.
\end{abstract}

Keywords: Road assessment, road inspection, stereo vision, evaluation of road condition, image processing and pattern recognition

Przestano do redakcji: 07.06.2016 r.

Przyjęto do druku: 30.06.2016 r.

DOI: 10.7862/rb.2016.91 